\title{
A BIBLIOGRAPHY OF THE HISTORY OF SURGICAL ANAESTHESIA IN CANADA SUPPLEMENT TO DR ROLAND'S CHECKLIST
}

\author{
AKitomo MatSUKI, M.D. ${ }^{\circ}$ AND ElemÉr K. Zsigmond, M.D. $\nmid$
}

CANADA was one of the earliest countries to introduce ether anaesthesia. Canadian physicians have contributed much to progress in the field. However, the history of surgical anaesthesia in Canada has not been fully documented.

The present bibliography is a supplement to Roland's preliminary checklist, which lacks many important articles published before 1900 . Hopefully it will augment studies of the history of surgical anaesthesia in Canada.

\section{GENERAL}

Editorial Note: Books etc. received during the month. Brit. Amer. J. Med. Phys. 2: 226 (1846).

This shows Boston Medical and Surgical J. including Bigelow's paper on ether anaesthesia is brought to Canada as early as in November 1846.

Medical News: Employment of Chloroform in Canada. Lancet (London) 1: 350 (1848). Report on Dr Nelson's lithotomy on a man under the influence of chloroform anaesthesia on February 12, 1848.

Editorials: The Jubilee of Anaesthesia. Canad. Practitioner 21: 844-845 (1896).

Fuller, R.C. \& AMHERST, N.S. The first authentic record of the use of chloroform on this side of the Atlantic. Canad. Pharmaceut. J. 58: 118-119 (1924).

The content is almost the same as MacKenzie's article. Dr Almon was not the first to use chloroform, Dr C. Harris of Baltimore used it for the first time outside the British Isles on about Dec. 19, 1847.

MurR, W.L. President's Address, Canadian Society of Anaesthetists. Canadian Practitioner 49: 420-426 (1924).

In this article, Muir describes how Dr Ingaris performed an operation under anaesthesia produced by laudanum and rum. Muir also describes chloroform anaesthesia by $\operatorname{Dr} A$ lmon and Mr Frazer.

Johnston, S. The growth of the specialty of anaesthesia in Canada. Canad. Med. A. J. 17: $163-165$ (1927).

Wenster, W. Notes on the development of anaesthesia in Western Canada. Canad. Med. Assoc. J. 17: 727-728 (1927).

Brief comment on the history of anaesthesia in Winnipeg and Vancouver.

Rolland, P. L'evolution de l'anesthesie. J. Canad. Dent. A. 8: 47-54 (1946). General history of anaesthesia.

SHIELDS, H.J. Account of the history of anaesthesia in Canada. Brit. M. J. 2: 129 (1955).

GrifFith, H.R. Fifty years of progress in surgery and anaesthesia. Canad. Nurse 54: 540-542 (1958).

'Instructor in Anesthesiology, Department of Anesthesiology, University of Hirosaki School of Medicine, Hirosaki, Aomori-Ken, Japan. Previously Senior research associate, Department of Anesthesiology, University of Michigan Medical Center, Ann Arbor, Michigan.

tProfessor of Anesthesiology, Department of Anesthesiology, University of Michigan, Ann Arbor, Michigan, U.S.A. 


\section{ANAESTHETICS}

Editorial Note: Chloroform. Brit. Amer. J. Med. Phys. Sci. 3: 278 (1848).

"Two instances of the application of this anaesthetic agent have occurred in this city within the last week - one a case of parturition, reported in this number by Dr Holmes, the other an amputation at the Montreal General Hospital, by which its soporific powers were most successfully brought into play. This case, we hope, will be reported also, and we therefore forbear anticipating any of Dr Sutherland's remarks on it. From what we have seen, we consider it as more valuable in its effects than ether, and (which is of some moment) less expensive. It is easily prepared; and for the benefit of our country subscribers, who may have difficulty in obtaining it from this city, in which it is largely manufactured by S.J. Lyman and Co., we give the following formula: Take of chloride of Lime four ounces, Alcohol one ounce, Water twelve ounces-mix in a capacious retort/and distil with a moderate heat. Two fluids come over, one of which, oily and heavier than the other, collects at the bottom of the receiver properly adapted to the retort. This is the Chloroform, and requires to be separated by in the first instance, a decantation of the super-natant fluid, and to be purified and rectified, in the second, by a re-distillation from Chloride of Calcium. The quantity thus obtained is small. The secret of its economical manufacture consists in the employment of large quantities of the materials. We refer our readers to the Periscopic Department for fuller quotations from our British exchanges on the subjects."

Campbell, F.W. On the Administration of Chloroform. Canad. Med. J. I: 157-161 (1865).

Rosebrugh, A.M. Chloroform. Dominion M. J. 1: 64 (1868-9), 2: 84 (1869-70).

ATHerton, A.B. On the exhibition of chloroform. Canad. Lancet 5: 114-116 (1872-3).

Editorial: Ether Chloroform. Canad. Lancet 5: 256-258 (1872-3).

CAREY, R.H. On the advantages of ether over chloroform as an anaesthetic agent. Canad. Lancet 5: 331-334 (1872-3).

Coleman, W.S. The administration of chloroform. Canad. Lancet 5: 616-624 (1872-3).

Nice review article on chloroform anaesthesia.

Pope, J.W. Chloroform in heart disease. Canad. Med. Rec. 2: 189 (1873-74).

Saint-Germain, M.De. Anaesthesia in children. Canad. J. Med. Sci. 4: 48-54 (1879).

Hincston, W.H. Certain anaesthetics. Canad. Med. Rec. 8: 225-228 (1880).

Editorial: Ether as an Anaesthetic. Canad. Lancet 10:62 (1878).

MACDonNell, R.L. The administration of chloroform. Canad. Med. Surg. J. 9: 11-19 (1880-81).

This paper mentions almost fatal cases of chloroform anaesthesia.

Gaynor, J.J. Chloroform as an anaesthetic - Its physiological action and therapeutic value. Canad. Lancet 16:65-70 (1883).

This article describes physiological action and mentions 13 substantial rules when giving chloroform anaesthesia.

WooD, C.A. Notes on the use of ether in obstetrics. Canad. Med. Rec. 12: 73-76 (1884). A total of 26 cases of obstetrical anaesthesia are mentioned.

Editorial: Our Choice of Anaesthetics. Canad. Practitioner 10: 150-151 (1885).

This gives eight general rules for administration of anaesthetics.

SMITH, L. The A.C.E. mixture. The best anaesthetic in obstetrical practise. Canad. Med. Rec. 14: 337-341 (1885).

A mixture which is composed of alcohol, chloroform and ether, in proportions of 1,2 and 3 of each, respectively, is highly recommended for obstetrical anaesthesia.

Editorial: Local Anaesthetics. Mont. Med. J. 17: 226-227 (1888).

Editorial: Anaesthesia by Chloroform. Canad. Practioner 17: 334 (1892).

BaLfour, J.D. Administration of chloroform and the dangers incident hitherto. Montreal Med. J. $21: 663-676(1892-93)$. 
Campbell, G.G. The pulse and respiration during ether anaesthesia with Clover's inhaler. Canad. Med. Rec. 23: 71-81 (1894-5).

Campbell, G.G. Anaesthesia in a case with diminished breathing area. Mont. Med. J. 24: 18-19 (1895-6).

Freeman, J. Chloroform or Ether? Canad. Practitioner 21: 581-587 (1896).

Scaddinc, H.C. The selection of an anaesthetic. Canad. Practitioner 23: 84-87 (1898).

G.S.R.: A suggestion for anaesthetics. Canad. Practitioner 24: 357 (1899).

"I have been in the habit for the past two years of having a little eau de cologne or other perfume dropped on the inhaler to begin with; then a few minutes chloroform is added."

\section{COMPLICATIONS}

Editorial: Death from chloroform. Medical Chronicle (Montreal) 5: 425-427 (1858).

This first death due to chloroform anaesthesia occurred on February 1, 1858.

Editorial: Death from chloroform. Canad. M. J. 3: 380 (1867).

SAUNDERS, H.J. Remarks on a case of chloroform poisoning. Canad. Lancet 6: 209-210 (1873-74).

WADE, W. Nelaton's method of resuscitation from chloroform narcosis - successful case. Canad. Lancet 7: 165-166 (1875).

Coverton, C.W. Successful case of resuscitation from chloroform narcotics. Nelaton's Method. Canad. Lancet 7: 193-194 (1875).

News: Death from chloroform. Canad. Med. Rec. 6: 20 (1877).

Death occurred by chloroform anaesthesia in Toronto General Hospital on July 18, 1877.

News: Death from chloroform. Canad. Lancet 10: 157 (1878).

News: Death from chloroform. Canad. Lancet 11: 313 (1879).

Editorials: Death from chloroform. Canad. Lancet 12: 157-158 (1880).

News: Another death from chloroform. Canad. Lancet 12:349 (1880).

Woolverton, A. Death under ether. Canad. Med. Surg. J. 9: 508-509 (1880-1).

LACrosse, E. Death under chloroform. Montreal Med. J. 19: 919-920 (1880-81).

Garilien, A.C. The case of sudden death during the first stage of chloroform. Canad. Lancet 13: 231-232 (1881).

Atherton, A.B. Case of chloroform poisoning. Canad. Lancet 13: 301-302 (1881).

Nelson, C.E. Dangerous inhalation of nitrous oxide gas. Canad. Med. Rec. 9: 193-194 (1881).

News: Death from chloroform. Canad. Lancet 15: 127 (1883).

Editorial: Chloroform death. Canad. Med. Surg. J. 16: 248-249 (1887).

"Two grave mistakes were made: 1st, the employment of chloroform instead of ether. 2nd, the failure to use those means which science has demonstrated to be the most efficacious in restoring a failing Circulation."

Editorial: Death from chloroform. Canad. Lancet 19: 281-282 (1887).

"The danger of anaesthetics are chiefly three, viz: paralysis of the respiratory centre, from an overdose, paralysis of the heart, from a too concentrated chloroform vapor and a combination of chloroform narcosis and shock."

Editorials: Death from chloroform. Canad. Practitioner 18: 309 (1893).

Ross, J.F.W. Heart from chloroform poisoning case. Canad. Practitioner 21: 437-438 (1896).

Editorials: Danger of chloroform. Canad. Practitioner 22: 382-383 (1897).

William, J.A. Inertia of the uterus following the use of chloroform. Canad. Practitioner 22: 436 (1897).

Editorials: Death from chloroform. Canad. Practitioner 22: 209-210 (1897).

RudolF, R.D. A note on death from chloroform. Canad. Practitioner 23: 82-83 (1898).

Oldrught, H.H. Anaesthesia and analgesia. Dominion Medical Monthly 10: 134-136 (1898). 


\section{MISCELLANEOUS}

O'Reilly, C. Anaesthetic requirements. Canad. J. Med. Surg. 1: 154 (1897).

Possibly the first anaesthesia chart in Canad. A revised anaesthesia chart appeared in 1901 (Canad. Lancet 34: 636-637 (1901).

Cassidy, J.J. Anaesthetic requirements. Canad. J. Med. Surg. 1: 176 (1897). Brief comment on O'Reilly's anesthesia chart.

Editorial: The compensation of the anaesthetist. Dominion Med. Monthly 14: 87-88 (1900).

"Where an operator receives $\$ 20.00$ for an operation, his assistant the joyful recipient of probably $\$ 20.00$ to $\$ 25.00$, and the poor anaesthetist $\$ 5.00$ with perhaps in some cases $\$ 10.00 . "$

Abrahams, S. On oxygen gas as an antidote to the deleterious effects of anaesthetic agents. Canad. Med. J. 1: 667 (1852-53).

\section{REFERENCE}

1. Roland, C.G. Bibliography of The History of Anaesthesia in Canada: Preliminary checklist. Canad. Anaesth. Soc. J. 15: 202 (1968). 